Review Article

\title{
Impact of air pollution and global warming on human health: an urgent need to mitigate by stake- holders
}

\section{Introduction}

Air Pollution global warming and climate change are inter related and play a major role in causing increased Airway allergies which are the earliest onset non communicable disease with tremendous psychosocio-economic health burden globally. They will be the defining issues for our health system in the $21^{\text {st }}$ century. Nearly 8 million people die from air pollution annually. ${ }^{1}$

We need 420litre of oxygen per day and we exhale 350litre of Carbon Di Oxide. To get this we have to breathe 10,000litre of air per day and to carry the oxygen for every part of the body we need 10,000 litres blood circulation every day. This gas exchange occurs in over 600 million alveoli in lungs which are lined with thin membrane of 0.3 micron. The air we breathe from atmosphere to reach alveoli for gas exchanges is carried by patent branching bronchial tubes over 100-200million. Our children suffer more from air pollution due to their anatomic and physiologic reasons (Table 1).
Volume I Issue 6 - 2018

\author{
H Paramesh \\ Pediatric Pulmonologist and Environmentalist, Lakeside Centre \\ of Health Promotion and Lakeside Education Trust, Indian \\ Institute of Science (I.I.Sc), India
}

Correspondence: H Paramesh, MD, Pediatric Pulmonologist and Environmentalist, Lakeside Centre of Health Promotion and Lakeside Education Trust, Distinguished Scientist/Professor Divecha Center for Climate Change, Indian Institute of Science (I.I.Sc) Bangalore, India, Email drhperamesh@gmail.com

Received: November 02, 2018 | Published: December II, 2018

Table I The main source of air pollution ${ }^{2}$

\begin{tabular}{|c|c|c|}
\hline Outdoor Air Pollution & Indoor Air Pollution & \\
\hline & Aero- Biological & Irritants \\
\hline \multicolumn{3}{|l|}{-Automobile exhaust } \\
\hline \multicolumn{3}{|l|}{ - Affect airways - } \\
\hline Nox, $\mathrm{SO}_{2}, \mathrm{O}_{3}, \mathrm{SPM}$ & - Dustmite- $60.00 \%$ & - Tobacco Smoke \\
\hline Photochemical oxidants & - Cockroach $-25.00 \%$ & - Mosquito Coil Burning \\
\hline - Toxic substances - & - Fungi $-07.50 \%$ & - Cooking Fuel \\
\hline CO, Lead & - Pollens $-07.50 \%$ & $\begin{array}{l}\text { - Formaldehyde Voaltile compounds from furniture made from } \\
\text { compressed wood, panel boards etc. }\end{array}$ \\
\hline - Carcinogenic - & - Pets- $05.00 \%$ & \\
\hline \multicolumn{3}{|l|}{ Benzene, PAH,Aldehydes. } \\
\hline \multicolumn{3}{|l|}{ - Power plant emission } \\
\hline \multicolumn{3}{|l|}{ - Open burning of solid waste } \\
\hline \multicolumn{3}{|c|}{ - Construction related activities - dust } \\
\hline \multicolumn{3}{|l|}{ - Mining activities } \\
\hline - Pollens, fungi. & & \\
\hline
\end{tabular}

\section{The main source of air pollution are ${ }^{2}$}

The air pollution pyramid can depict the progress of ill effects from silent airway obstructions without symptoms to hospital visits, to emergency visits, to hospitalizations, and death ${ }^{3}$ (Tables 2-4). 
Table 2 Outdoor air pollutants 4,5

\begin{tabular}{|c|c|c|}
\hline Chemical & Source & III Effect \\
\hline CO & \multirow{2}{*}{$50 \%$ of all our air pollution motor vehicles } & Low level of oxygen[Hypoxia] \\
\hline Carbon Mono Oxide & & No effect of Lung Function \\
\hline $\mathrm{SO}_{2}$ & \multirow{4}{*}{ Motor Vehicles, Power Plants,75\% from fossils fuels } & -Airway Inflammation both upper and lower airways. \\
\hline \multirow{3}{*}{ Sulphur Di Oxide } & & - Decreases Mucus clearance \\
\hline & & - I0 fold sensitivity to asthma \\
\hline & & - Increase resistance to air flow \\
\hline NOx & \multirow{3}{*}{ Motor Vehicles } & - Increase resistance of flow of air \\
\hline \multirow{2}{*}{ Oxides of Nitrogen } & & $60 \%$ increase in asthma attack \\
\hline & & - Increase sensitivity to dust mites. \\
\hline $\mathbf{O}_{3}$ & \multirow{3}{*}{$\begin{array}{l}\text { Motor Vehicles slow moving vehicles with higher } \\
\text { emission in summer with bright sunlight and low } \\
\text { wind velocity. }\end{array}$} & - Extreme irritant to respiratory tract \\
\hline \multirow[t]{2}{*}{ Ozone } & & $\cdot$ There is $43 \%$ increase in asthma. \\
\hline & & -Asthma increase in summer by 16 times in 15 years. \\
\hline \multirow{3}{*}{$\begin{array}{l}\text { SPM I0 to } 2.5 \text { micron } \\
\text { suspended particulate } \\
\text { matter }\end{array}$} & \multirow{3}{*}{ Diesel Vehicle } & -Airway Inflammation \\
\hline & & - Cardiovascular disease \\
\hline & & - Cancer \\
\hline \multirow[t]{3}{*}{ Lead } & \multirow{3}{*}{$\begin{array}{l}80 \% \text { from Automobile Exhaust from leaded petrol, } \\
\text { paint, battery, crystal glass, enamel jewelry }\end{array}$} & -Abdominal cramps \\
\hline & & Anemia \\
\hline & & - Convulions coma and death. \\
\hline
\end{tabular}

Table 3 Indoor air pollutants 4,5

\begin{tabular}{lll}
\hline Agents & Source & Ill Effect \\
\hline $\begin{array}{l}\text { Aerobiological } \\
\text { Dust mites }\end{array}$ & $\begin{array}{l}\text { Bed, blankets, pillows, stuff toys, carpets, upholstered } \\
\text { furniture, heavy draperies }\end{array}$ & $\begin{array}{l}\text { Allergic nose problem, sinusitis, adenoidal hyper trophy, } \\
\text { asthma }\end{array}$ \\
$\begin{array}{l}\text { Cockroach } \\
25 \%\end{array}$ & Kitchens, stores, drains, garbages, ill maintained houses & Allergic rhinosinusitis, asthma, \\
Fungus & Wet humid, ill ventilated houses, basement, attics, & \\
$7.50 \%$ & Shower curtains, indoor plants not exposed to sun light & Allergy respiratory problems asthma. \\
Pollens & Tree pollens- Jan-Apr & \\
$7.50 \%$ & Grass pollens-July-Nov & Allergy respiratory disease, seasonal asthma. \\
& Weed Pollens- Nov-Jan & \\
Pets & Cats are more allergic, skin scales, urine and saliava & $\begin{array}{l}\text { Allergies respiratory problems. Improved cases. Dogs are } \\
\text { stress busters }\end{array}$ \\
\hline
\end{tabular}

Table 4 Indoor Air Pollutants

\begin{tabular}{lll}
\hline Irritants & Source & III Effects \\
\hline Tobacco Smoke & From Smoking & Fetus in mothers womb is affected by third hand \\
& & $\begin{array}{l}\text { Smoke. Prematurity, low lung capacity, more wheezing, } \\
\text { blood pressure and heart problem and cancer }\end{array}$ \\
Mosquito coil & Burning of coils to prevent mosquito & One coil is equivalent to burning of 70-I00 ciggrates \\
bite & Cooking in Chulhas with fire woods & Nearby 400 ciggrate smoking ill effect \\
$\begin{array}{l}\text { Chulhas } \\
\begin{array}{l}\text { Formaldehyde Volatile organic } \\
\text { compounds(VOC) }\end{array}\end{array}$ & $\begin{array}{l}\text { Modern furniture made of compressed } \\
\text { wood and panel boards etc. }\end{array}$ & $\begin{array}{l}\text { Extremely irritant to respiratory tract and has } \\
\text { cumulative effects. }\end{array}$ \\
\hline
\end{tabular}




\section{Causes for climate change and global warming to increase airway allergies}

It has been observed that during the preindustrial times before 1800; the carbon-di-oxide $\left(\mathrm{CO}_{2}\right)$ emission was from respiration of humans, animals, volcanic eruptions, decomposition of dead materials, burning and from forest fires. Now in addition to we are adding by rapid urbanisation, ${ }^{4}$ automobile emission and deforestation, intense animal's agriculture to meet the need of non-vegetarians. ${ }^{5}$ It is the burning of fossil fuel in large quantity contribute for the $\mathrm{Co}_{2}$ concentration and global warming. ${ }^{6}$

The temperature of our planet earth is raising mainly due to increased concentration from greenhouse gases concentration, such as carbon-di-oxide, nitrous oxide and methane which will prolong the flowering season and increase the allergic season from pollens. In addition new plants with new pollens will emerge.

The global warming produces of potent pollens and the deisel particle coated pollens are 50times more potent and produce stronger and prolonged symptoms of allergy. ${ }^{7}$

Sudden change in the temperature causes increase sensitivity to develop respiratory and ocular symptoms, decrease in lung functions (FEF) and more pronounced inflammatory nasal response. Both early and late phase phenomenon are expected to occur. ${ }^{2}$

It takes 4 weeks for lungs to recover from the ill effects of inhaled of urban polluted for $30 \mathrm{mins}$.

WHO reported that in the year 2014 that there are 1600 cities around the world which have dirty atmosphere. Thirteen for the top twenty most polluted cities in the world are situated in India Delhi pollution level of PM 2.5micron is 153 that are 6times higher than recommended by WHO. The major cause of air pollution and global warming and climate change in our country are ${ }^{8}$

a) Increase vehicular traffic: $66.28 \%$ of total consumption of diesel

b) Coal powered thermal plants: Account for $60.72 \%$ of India's total power generation

c) Use of biomass: $87 \%$ in rural $26 \%$ is urban households

d) Use of Kerosene: $30 \%$ of rural households

It is also predicted that we can save $\$ 105$ billion by 2030 if we can reduce the particulate emission by $30 \%{ }^{8}$

\section{Health issues of Air pollution observed in our study}

Air pollution both outdoor and indoor air pollution have impact from womb to tomb many occasion it is difficult to separate them distinctly.

There is significant increase in upper respiratory allergies and its comorbidities such as -

A. Allergic rhinitis increased in general pediatric population from $22.5 \%$ to $27.5 \%$ between $1994-1999$ and in asthmatic children it is gone up from $75 \%$ in 1999 to $99.6 \%$ in $2011.9,10$

B. The comorbidities of allergic rhinitis like otitis media is $22.5 \%$; sinusitis is $34.8 \%$ and conjunctivitis is $27.5 \% .{ }^{9,10}$

The lower respiratory airway allergy: Asthma is also increased $9 \%$ to $26.1 \%$ from 1979 to 2016 as shown in Figure 1.

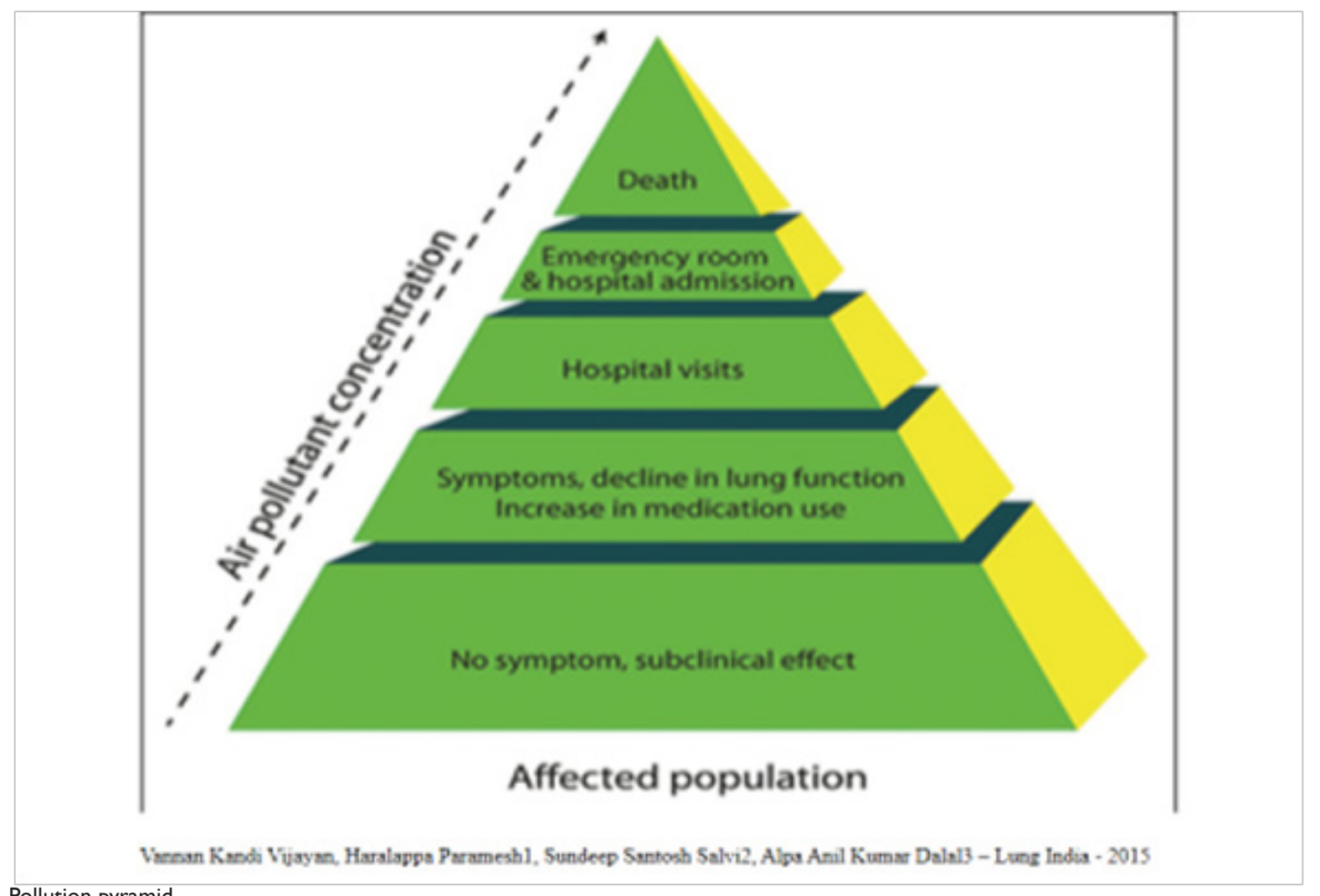

Figure I Pollution pyramid 
Children from heavy traffic area school suffer more asthma and it further increase in low socioeconomic children. ${ }^{9}$ Urban children suffer more in asthma than rural children as shown in Figure 2. ${ }^{9}$ Emergency room visit from asthma increased by $100 \%$ during Diwali festival where bursting of crackers happen by increasing the air pollution by sulphur-di-oxide as shown in Figure 3. ${ }^{10}$

\section{Trends of Asthma Prevalence in Bangalore}

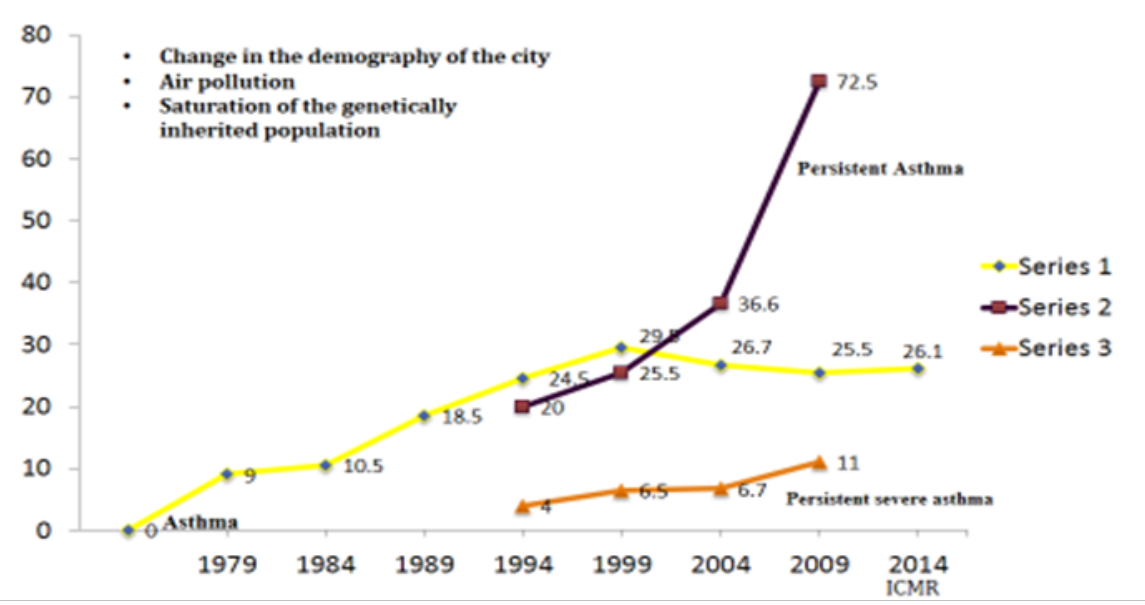

Figure 2 Asthma prevalence in Bangalore.

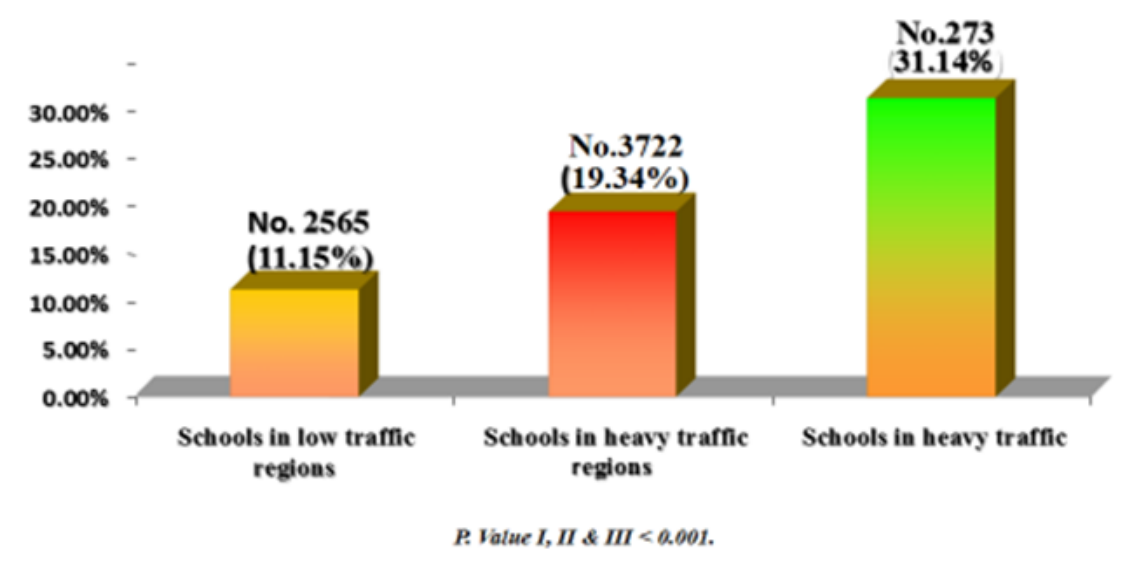

Figure 3 Children of heavy traffic school areas suffer more from asthma.

Asthma is increased in summer season from $2.8 \%$ to $28.8 \%$ between 1994-2009 and is hypothesised due to secondary production of increased ozone level Figure $4 .{ }^{11}$ Double the number of traffic police personnel suffer from air pollution than non-traffic police personnel as shown in Figure $5 .{ }^{12}$ Use of non-commercial cooking fuel has shown 6 times more prevalence of asthma Figure 6. Children living in single room, ill ventilated huts and use of non-commercial cooking fuel showed $10 \frac{1}{2}$ times more prevalence of Acute respiratory infection Figure $7 .{ }^{10}$ Single person smoking in the house increases the prevalence of asthma by 3 times Figure $8 .^{10}$

Chronic cough over 2 weeks with comorbidities are increased from 8 to $21.25 \%$ between $1999-2017 .^{12,13}$

Wheeze in preschool children is a global phenomenon. Nearly $77.7 \%$ of our children under 5 yrs are wheezers in them $26.3 \%$ are below 1 year of age. ${ }^{14}$ Wheeze in preschool children is increased by 4 fold by prenatal exposure to SPM 2.5 micron particles from $35.5 \mu$ to 53.5micron Figure 9. ${ }^{15}$

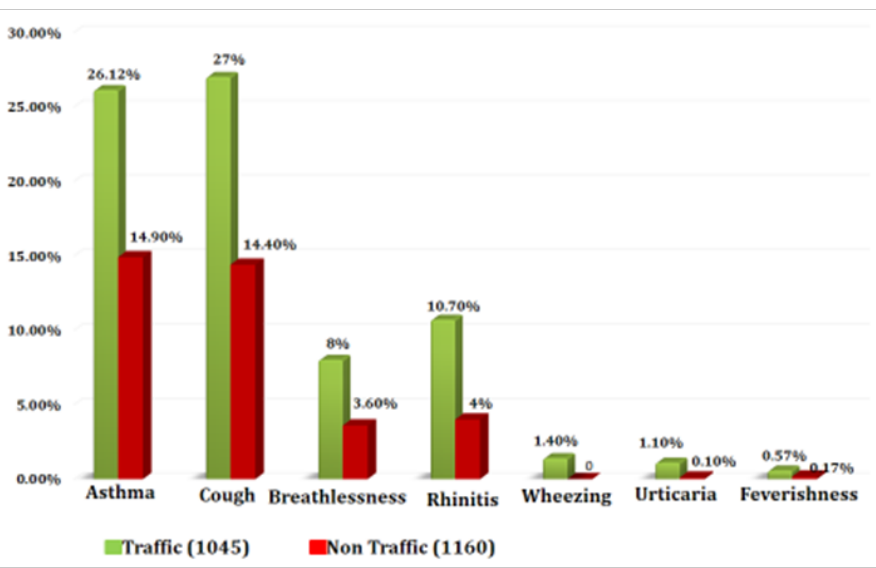

Figure 4 Traffic Police suffer mare from Air Pollution than Non - Traffic Police. 


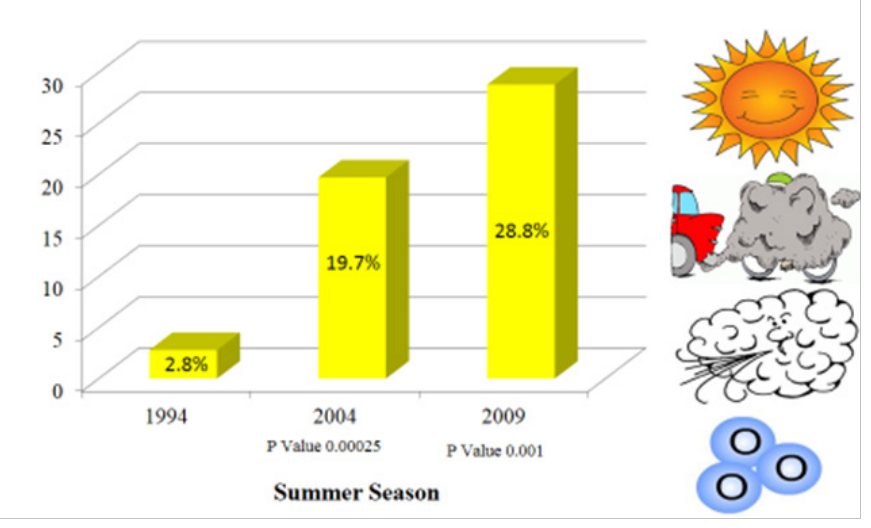

Figure 5 Changing Seasonal Pattern of Asthma Episodes

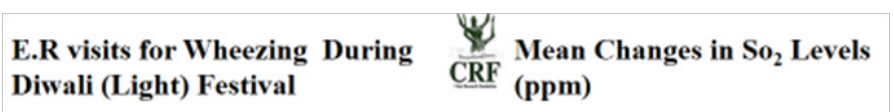

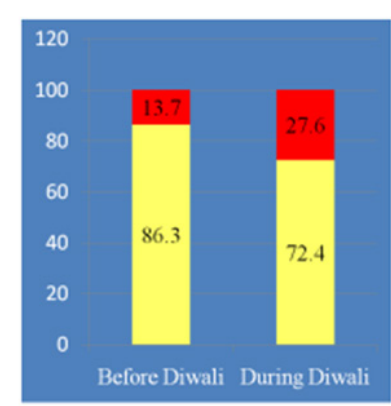

P Value : 0.064

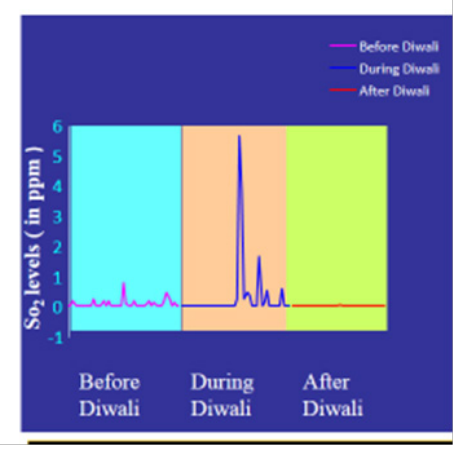

Figure 6 E.R visits for Wheezing during Diwali Festival and Mean Change in $\mathrm{So}_{2}$ Levels.

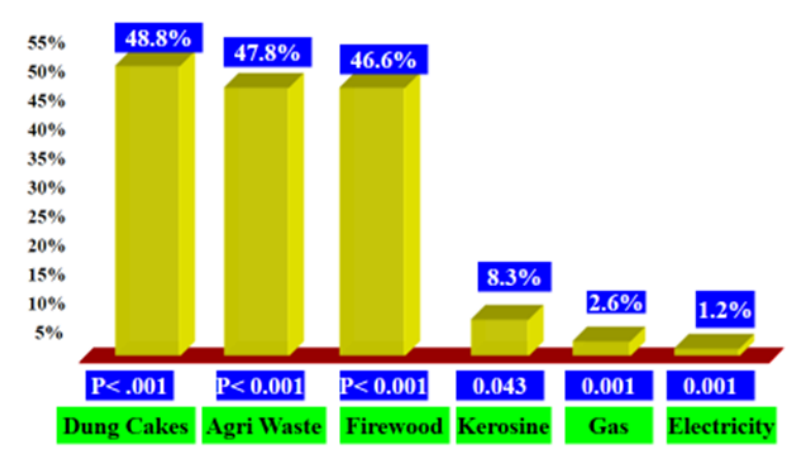

Figure 7 Cooking FuelV/s Prevalence of Asthma in Children.

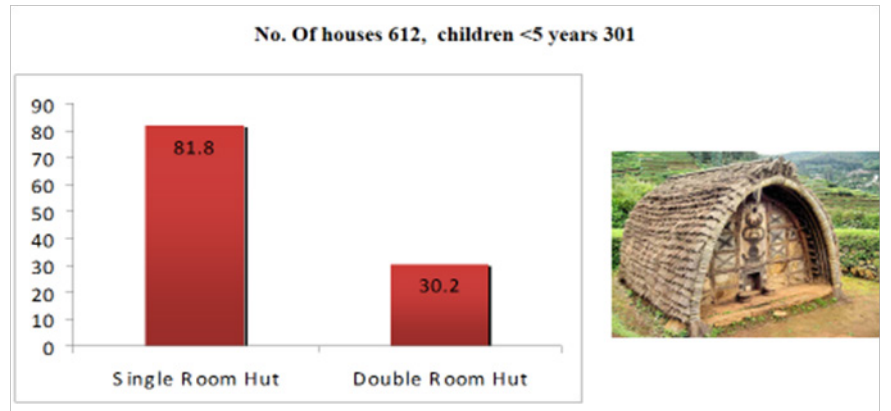

Children living in single room are $\mathbf{1 0 . 5}$ times more likely to develop respiratory infection when compared to children living in double rooms. $\mathrm{P}<0.001^{* *}$

Figure 8 Point Prevalence of respiratory infection/indoor pollution A Rural Study.

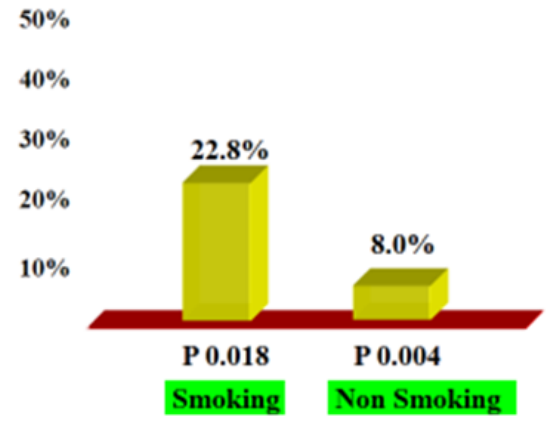

Figure 9 Cigarette Smoking Parents V/s Asthma Prevalence in children.

\section{Measures to mitigate air pollution and global warming: ${ }^{16}$}

a) Quality education of stake holders on the magnitude of the disease burden on psycho socio economic front with convincing data.

b) Reduce air pollution by setting guidelines on both outdoor and indoor air pollution.

c) Reduce personal automobiles and encourage mass transport. Reduce usage of fossil fuel which is the major contributor for air pollution, global warming and climate change. Look out for electric motors vehicles in future

d) Finding out new energy source - Preferably solar energy, atomic energy with strict safeguarding the waste management

e) Increase greenery: Planting more trees to reduce Carbon dioxide and produce more oxygen. One full grown tree gives free oxygen for 4 people per year. Ocean agriculture can enhance carbon sequestration and enhances the fish population. However one has to observe for biological oxygen demand.

Indoor plants helps in absorbing the formaldehyde, volatile organic compounds which are highly irritants to respiratory tract emitted from furniture's from compressed woods, panel boards carpet glue etc.

The recommended plants are - firn, anthurium, bamboo, chrysanthemum and money plants. Please note that these plants should be exposed to sunlight and tray of water should be removed weekly to avoid fungal growth and to mosquito breeding.

i. For sustainability of the cities and communities one has to plan the cites to match the need and supply with good roads, clean drains, clean chimneys, good footpaths for children and senior citizen, maintain parks, playgrounds, plant trees and having bicycle paths are a must.

ii. We have to highlight the economic burden to policy makers and implementing strict guidelines to prevent air pollution how much we can gain economically over the years

iii. Social determinants dictate terms for sustainability. We should aim to reduce the population growth and encourage family planning. No government could able to match the needs of rapid growing demands.

iv. When authorities and policy makers fail to control air pollution the society should activate our legal system to achieve societal needs

v. Air pollution produce inflammation of airways by oxidative stress hence we have to recommend our patients to use 
foods with more oxidants like fresh fruits, vegetables, butter and encourage yogurt, curds to replenish protective germs in the gut, fish and other omega 3 fatty acid food to reduce inflammation. Always encourage local traditional food habits. ${ }^{17}$

\section{Conclusion}

a) Airway allergic diseases are the earliest onset non communicable disease of environment origin with major psycho-socio-economic burdens.

b) Society should involve and determine the health care management by the collective efforts of all stake holders for sustainability.

c) Influence the policy makers with quality education in budgeting to promote research on traditional local values on care along with cure

d) It demands think locally act locally and propagate the results globally

e) LINK for progress of health science - include ethical participation of practitioner's academicians, researchers and pharma companies.

f) With new technologies interventions and energy sources with urgent need to put all the efforts by all stake holders we can mitigate air pollution, global warming climate change by 2030 .

\section{Acknowledgments}

None.

\section{Conflicts of interest}

The authors declare no conflicts of interest in this work.

\section{References}

1. Reducing Global Health Risks through mitigation of short-lived climate pollutants. 2015

2. Paramesh H. Scenario of respiratory ailments in children with particular reference to asthma in Bangalore. Recent trends in aerobiology, allergy and immunology. Oxford and IBH; 1994:207-216.

3. Vannan Kandi Vijayan, Haralappa Paramesh, Sundeep Santhosh Salvi, et al. Enhancing Indoor Air Quality-The air filter advantage: Lung India. 2015:32(5).
4. Foundation HP on health state of environmental report and action plan2003, department of forest, ecology and environment, government of Karnataka World Banak Project. Bangalore: Abhiman Publication; 2004:217-226

5. National commission of Macroeconomics and health, Govt. of India. 2005.

6. The visual guide to understanding climate and environment. Mauna Loa observatory, $\mathrm{CO}_{2}$. Information analysis center Earth system Research Laboratory. 2007.

7. D' Amato G, Holgats S T, Pavanker R, et al. Metetological conditions climate change. World Allergy organ. 2015;8(1):25.

8. Air pollution in India: Impact policy analysis and remedial measures by government.

9. H Paramesh. Epidemiology of Asthma in India. Indian Journal of Pediatric. 2002;69:309-312.

10. H. Paramesh. outdoor and indoor air pollution on respiratory health, advances in respiratory medicine Academy in Respiratory medicine. Ed. Ps. Shankar. 2013:1-10.

11. H Paramesh. Asthma and environment. Indian Journal of Pediatrics (Special Supplement). 2006;73:S51-S55.

12. H Paramesh. Airway Disease Education \& Expertise (ADEX) NEXT Working Group Recommendations-Persistent (Chronic) Cough in Pediatric Practice; NIJP Index Copernicus International. 2017. 6 p.

13. Paramesh $\mathrm{H}$, Rashmi $\mathrm{C}$ Paramesh. Overview in the managemen of persistent cough in pediatric practice; MOJ Curr Res \& Rev. 2018;1(4):154-157.

14. H Paramesh. Round the World Preschool Wheeze. Lancet Respiratory. 2017.

15. Weislow Jedry Chowski, et al. Intl. Jourl of Environment and Health. $2008 ; 2,3(3-4)$.

16. H Paramesh. Allergic disorders in the working environment of Traffic and Non traffic police personnel, Proc XI National Symposium on environment. 2002:156-157.

17. H Paramesh. Air pollution and allergic airway diseases: socia determinants and sustainability in the control and prevention. Indian $J$ Pediatr. 2018:85(4):284-294. 